\title{
Determination of the antibacterial efficacy of several antiseptics tested on skin by an 'ex-vivo' test
}

\author{
SYNDIE MESSAGER, P. A. GODDARD*, P. W. DETTMAR* and J.-Y. MAILLARD \\ Welsh School of Pharmacy, Cardiff University, King Edward VII Avenue, Cardiff CF10 3XF and * Reckitt and \\ Colman Products, Dansom Lane, Hull HU8 7DS
}

\begin{abstract}
There are many skin antiseptics commercially available. Although their antibacterial activity has often been well studied [1], their potential effectiveness on skin remains poorly documented. To date, in-vivo protocols designed for the testing of the antimicrobial efficacy of antiseptics cannot use, for ethical reasons, pathogenic bacteria or new formulations whose toxicity in human subjects is unknown. An 'ex-vivo' test was recently developed to overcome these problems. Freshly excised human skin from abdominal or breast reduction was placed in a diffusion cell containing a maintenance medium in the recipient compartment. A bacterial inoculum was then applied to the stratum corneum and, after a drying step, antiseptic formulations were evaluated for their antimicrobial activity. Several micro-organisms were investigated: - Staphylococcus aureus, methicillin-resistant $S$. aureus (MRSA), Enterococcus faecalis, vancomycinresistant Ent. faecium (VRE), S. epidermidis, Pseudomonas aeruginosa and Escherichia coli - with several biocides - para-chloro-meta-xylenol (PCMX, active compound of Dettol), povidone iodine, triclosan (in isopropanol) and chlorhexidine. Results from the ex-vivo test were compared with results obtained in suspension and glass-carrier tests. The bactericidal activity of the biocides depended upon the test performed and results were generally significantly different from one method to the other. All biocides tested in the suspension test achieved $>4 \log _{10}$ reduction in viable bacterial concentrations, apart from povidone iodine tested against Ent. faecalis and VRE. The antibacterial activity of biocides tested in the glass-carrier test was significantly lower than in the suspension test, with the exception of triclosan in isopropanol, which was as effective in both suspension and glass-carrier test. In the ex-vivo test, triclosan in isopropanol achieved a $\log _{10}$ reduction in viable bacterial concentration of 1.105-1.771 (with the exception of $P$. aeruginosa with $0.758 \log _{10}$ reduction). PCMX, povidone iodine and chlorhexidine achieved $\log _{10}$ reductions in viable bacterial concentration of $0.303-0.901$. Chlorhexidine tested against $P$. aeruginosa produced a $1.94 \log _{10}$ reduction in concentration. These results confirm previous observations about the need for testing the antimicrobial activity of antiseptics on skin surface to determine their in-situ efficacy and encourage further the use of the ex-vivo protocol.
\end{abstract}

\section{Introduction}

The transfer of pathogenic bacteria via the hands of staff in health care centres is often the source of outbreaks of nosocomial infections. Hand-washing with a skin disinfectant is an important practice for reducing the risk of infection but, as has already been

Received 19 June 2000; revised version accepted 31 Aug. 2000.

Corresponding author: Dr J-Y. Maillard (e-mail: maillard@, cardiff.ac.uk). shown among hospital staff, hands are washed too seldom, the antiseptics used are often chosen randomly and hand-washing technique is poor [2]. Furthermore, frequent use of antiseptics and some scrubbing techniques can be the cause of skin irritation or allergies, which might explain in part the low frequency of hand-washing [3].

There are many skin antiseptics commercially available. However, the effectiveness of the products is usually investigated by in-vitro techniques, as their activity on human skin is difficult to assess. Indeed, 
only in-vivo trials can evaluate the efficacy of antiseptic products directly on human skin, thus retranscribing the 'in-use' practice. However, for ethical reasons, only non-pathogenic bacteria and products whose safety for human subjects is known can be tested in these in-situ studies. Furthermore, most studies performed in vivo with volunteers have shown some important variability in results. This is often due to the hand-washing techniques, which can vary significantly among subjects, rather than to the antiseptic tested [4].

There has been a search for a substitute for both in-vitro and in-vivo protocols because of the deficiencies and limitations of these tests; i.e., variability in results with clinical studies as well as limitation in micro-organisms and antiseptics to be tested. Furthermore, results from in-vitro techniques have to be taken into account cautiously as they have been shown to overestimate the antibacterial efficacy of biocides, as in the suspension test [5] or can sometimes be difficult to interpret because of the significant loss of bacterial cells caused only by pre-treatment, as in the glass-carrier test [5].

The aim of this study was to investigate the antimicrobial properties of several biocides commonly used in formulations with antiseptic properties against several pathogenic micro-organisms, including some antibioticresistant strains, by three different methods: a suspension test, a glass-carrier test and the ex-vivo protocol.

\section{Materials and methods}

\section{Test organisms}

Pseudomonas aeruginosa (NCIMB 10421), Staphylococcus epidermidis (P69; Cardiff University), S. aureus Oxford (NCTC 6571), Escherichia coli K12 (NCTC 10538), Enterococcus faecalis (Q 33; Cardiff University), methicillin-resistant S. aureus (MRSA) (9543; Cardiff University) and vancomycin-resistant Ent. faecium (Z31901; VRE; University of Wales, College of Medicine) were grown overnight in Tryptone Soya Broth (TSB; Oxoid) at $37.1 \pm 0.45^{\circ} \mathrm{C}$ in a water bath (Gallenkamp) with constant agitation $(90 \mathrm{rpm})$. Stock cultures were made on Tryptone Soya Agar (TSA; Oxoid) plates and slopes, stored at $4^{\circ} \mathrm{C}$ and renewed once a week.

Viable bacterial concentration was determined by the drop counting method [5]. Briefly, a 0.1-ml sample was serially diluted in sterile phosphate-buffered saline (PBS; Sigma) and 10- $\mu$ l drops were plated on to the surface of an over-dried TSA plate. After overnight incubation at $36.8 \pm 1.5^{\circ} \mathrm{C}$, colonies were counted and the viable bacterial concentration was expressed as $\mathrm{cfu} / \mathrm{ml}$.

\section{Chemicals}

The antimicrobial activity of the following biocides was investigated: PCMX 0.24\% w/v (Dettol diluted to $5 \%$; Reckitt \& Colman Hull, E. York), povidone iodine $2 \% \mathrm{w} / \mathrm{v}$ (Pov; Sigma), chlorhexidine 2\%w/v (CHX; Sigma), triclosan $0.5 \% \mathrm{w} / \mathrm{v}$ (TRI; Ciba Specialty Chemicals) in isopropanol (Sigma) $70 \% \mathrm{v} / \mathrm{v}$ and isopropanol (Sigma) $70 \% \mathrm{v} / \mathrm{v}$. These solutions were made fresh in sterile ultrapure water (Nanopure, Barnstead) and autoclaved according to the British Pharmacopeia procedure [6].

\section{Neutralisers}

Neutralising solutions used to quench the activity of disinfectants were based on the British Standard EN 1499 [7] and were made fresh in sterile ultrapure water (Nanopure); concentrations are given /L of TSB (Oxoid) and were as follows. Pov 2\% was neutralised by 'neutraliser A': polysorbate 80 (Sigma) $30 \mathrm{~g} / \mathrm{L}$, lecithin from eggs (Sigma) $3 \mathrm{~g} / \mathrm{L}$, L-histidine (Sigma) $1 \mathrm{~g} / \mathrm{L}$, sodium thiosulphate (Fisher) $5 \mathrm{~g} / \mathrm{L}$, lyophilised bovine albumin (Sigma) $1 \mathrm{~g} / \mathrm{L}$. TRI $0.5 \%$ in isopropanol $70 \%$ and isopropanol $70 \%$ were neutralised by neutraliser B: polysorbate $8030 \mathrm{~g} / \mathrm{L}$, lecithin from eggs $3 \mathrm{~g} / \mathrm{L}$, L-histidine $1 \mathrm{~g} / \mathrm{L}$, sodium thiosulphate $5 \mathrm{~g} / \mathrm{l}$. PCMX $0.24 \%$ was neutralised by neutraliser C: polysorbate $80150 \mathrm{~g} / \mathrm{L}$, lecithin from eggs $15 \mathrm{~g} / \mathrm{L}, \mathrm{L}-$ histidine $5 \mathrm{~g} / \mathrm{L}$, sodium thiosulphate $25 \mathrm{~g} / \mathrm{L}$. CHX 2\% was neutralised by neutraliser $\mathrm{D}^{\prime}$ : polysorbate 80 $30 \mathrm{~g} / \mathrm{L}$, lecithin from eggs $3 \mathrm{~g} / \mathrm{L}$, L-histidine $1 \mathrm{~g} / \mathrm{L}$.

\section{Suspension test}

The suspension test protocol was based on the British Standard EN 1276 [8]. Two controls were performed. First, to assess the antibacterial activity of the neutralisers, $1 \mathrm{ml}$ of bacterial inoculum $\left(2 \times 10^{8}-\right.$ $2 \times 10^{9} \mathrm{cfu} / \mathrm{ml}$ ) was added to $9 \mathrm{ml}$ of neutraliser and, after 5-min contact time, a serial dilution was made in sterile Eppendorf tubes containing PBS and the drop counting method was used to determined the number of surviving micro-organisms. Second, to assess the effectiveness of the neutralisers to quench the appropriate disinfectants, $1 \mathrm{ml}$ of disinfectant was added to $9 \mathrm{ml}$ of the appropriate neutraliser. After 1-min contact time, a 9-ml sample was removed and mixed with $1 \mathrm{ml}$ of a bacterial suspension. This solution was then serially diluted in Eppendorf tubes containing PBS and bacterial survival was determined by the drop counting method.

Antibacterial activity of the biocides was determined as follows: $1 \mathrm{ml}$ of bacterial inoculum $\left(2 \times 10^{8}-\right.$ $2 \times 10^{9} \mathrm{cfu} / \mathrm{ml}$ ) was added to $9 \mathrm{ml}$ of a biocide. After a 1-min contact time, $1 \mathrm{ml}$ of this mixture was added to $9 \mathrm{ml}$ of the appropriate neutraliser. A serial dilution of this mixture was made in Eppendorf tubes containing PBS, plated on TSA plates by the drop counting method and surviving bacteria were counted after overnight incubation at $36.8 \pm 1.5^{\circ} \mathrm{C}$. A 1 -min contact time was chosen for the three methods to follow procedures described in the British Standard EN 1499 [7]. 


\section{Glass-carrier test}

The glass-carrier test was based on a procedure developed elsewhere $[9,10]$. Briefly, $20 \mu \mathrm{l}$ of a bacterial inoculum $\left(2 \times 10^{8}-2 \times 10^{9} \mathrm{cfu} / \mathrm{ml}\right)$ were placed on to the glass surface at the bottom of a sterile bottle (autoclavable glass bottle; Fisher) and dried for $2 \mathrm{~h}$ in a laminar flow cabinet (FASTER, BHA 48). A $30-\mu 1$ sample of biocide was added on to the dried inoculum and, after 1-min contact time, $450 \mu 1$ of the appropriate neutralising solution were added. Surviving bacteria were resuspended in the neutralising solution and counted by the drop counting method.

The antibacterial activity of the drying process was investigated. After drying in a laminar flow cabinet for $2 \mathrm{~h}$, the dried bacterial inoculum was resuspended in $480 \mu \mathrm{l}$ of neutraliser or PBS. The number of surviving bacteria was determined by the drop counting method.

\section{Ex-vivo test}

The recently developed ex-vivo test [5] was used for testing the antimicrobial activity of biocides against the test micro-organisms on skin. Skin samples were obtained from patients undergoing plastic surgery, mainly breast and abdominal reductions. Donors' permission was obtained before surgery. Depending on the availability of the skin, tests were performed with either fresh or frozen skin. Fresh samples were stored in Earle's balanced salts solution (EBSS; Sigma) at $4^{\circ} \mathrm{C}$ and frozen samples at $-20^{\circ} \mathrm{C}$ until used.

Skin samples of c. $2 \mathrm{~cm}^{2}$ were placed on a diffusion cell containing $1 \mathrm{ml}$ of PBS in the recipient compartment to keep the dermis moist (Fig 1). An overnight bacterial culture $\left(20 \mu \mathrm{l}\right.$ of $\left.2 \times 10^{8}-2 \times 10^{9} \mathrm{cfu} / \mathrm{ml}\right)$ was inoculated on to the stratum corneum and dried for $3 \mathrm{~min}$ in a laminar flow cabinet. Biocide $(30 \mu \mathrm{l})$ was then added to the bacterial inoculum. After a 1-min contact time, $450 \mu \mathrm{l}$ of the appropriate neutralising solution were added on to the skin sample. Surviving bacteria were resuspended in the neutraliser and counted by the drop counting method. As human skin is not easily obtainable, skin samples were sometimes used twice. Before re-use, the skin surface was rinsed three times in sterile PBS.

Information about the donor, sex, age, sample origin, frozen or fresh skin, first or second use, as well as their permission were recorded and taken into account for the statistical analyses of the results.

Two controls were performed with the ex-vivo protocol. Resident flora was investigated by rinsing the skin surface with $500 \mu \mathrm{l}$ of PBS and then counted by the drop counting method. Also, to evaluate bacterial survival on skin, $20 \mu \mathrm{l}$ of bacterial inoculum $\left(2 \times 10^{8}-2 \times 10^{9} \mathrm{cfu} / \mathrm{ml}\right)$ were placed on to the skin, dried for $3 \mathrm{~min}$ in a laminar flow cabinet, resuspended with $480 \mu \mathrm{l}$ of PBS or neutraliser and counted by the drop counting method. For the re-used samples, a control was made to evaluate the remaining bacteria on skin after the first test by rinsing the skin surface with $500 \mu \mathrm{l}$ of PBS and counting remaining bacteria by the drop counting method.

Because of the limitation of the skin supply, the antibacterial activity of isopropanol $70 \%$ was assessed against only three bacterial strains: E. coli K12, $S$. aureus Oxford and MRSA.

Finally, skin viability was investigated by spectrophotometric measurement of the lactate dehydrogenase (LDH) activity with a diagnostic kit (Test EC 1.1.1.27, catalogue no. DG1340-K, Sigma).

\section{Statistical analyses}

Analyses of variance were performed with the Mini$\operatorname{tab}^{\circledR}$ software and were conducted at the $95 \%$ confidence interval. Five replicas were performed for

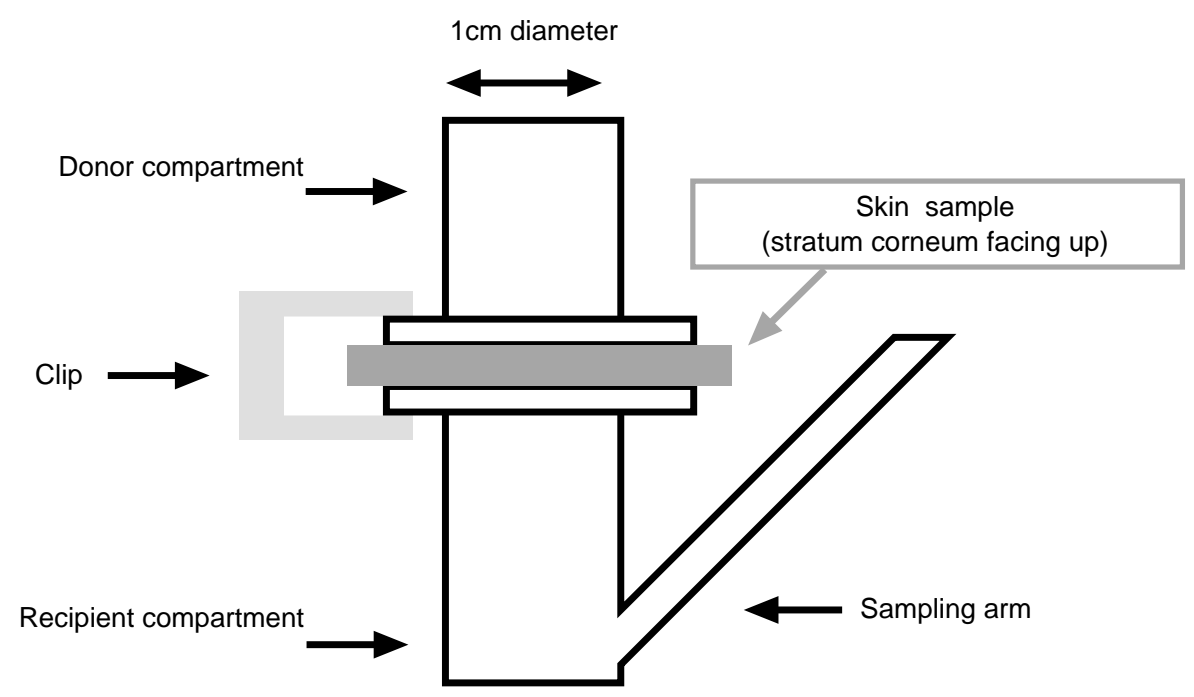

Fig. 1. Ex-vivo protocol. 
the suspension and the glass-carrier tests and at least three for the ex-vivo test.

\section{Results}

\section{Antibacterial activity of the neutralisers}

Table 1 shows the antimicrobial effect of the neutralisers against the bacterial strains investigated. The $\log _{10}$ reduction is calculated as $\log _{10}$ number of surviving cells $(\mathrm{cfu} / \mathrm{ml})$ after exposure to neutralisers $-\log _{10}$ number of cells in the control bacterial inoculum.

The neutralisers $\mathrm{A}, \mathrm{B}, \mathrm{C}$ and $\mathrm{D}$ did not reduce significantly $(p>0.05)$ the viable bacterial concentrations of the strains tested.

\section{Efficacy of neutralisers}

The neutralising solutions quenched effectively $(\mathrm{p}>0.05)$ the appropriate biocide at the concentration tested (data not shown). As an example, $0.13 \log _{10}$ reduction in bacterial titre was observed when the inoculum was added to a mixture containing both neutraliser D and CHX. This value was not significantly different from the control.

\section{Skin resident flora}

Some skin samples showed transient contamination, although the concentration of these bacteria did not exceed $10^{2} \mathrm{cfu} / \mathrm{ml}$. When contamination was observed, the concentration of contaminants was taken into account for the calculation of the concentration of the test organisms recovered after the tests.

\section{Bacterial survival on skin}

The concentration of surviving cells recovered in PBS, after the drying process on skin (ex-vivo test) or on glass (glass-carrier test), is shown in Fig. 2. These results were compared with that obtained in the suspension test where the bacterial cells were resuspended in neutraliser. There was no significant difference $(p>0.05)$ in the number of bacterial cells recovered with either protocol for VRE, Ent. faecalis and MRSA. However, S. aureus, S. epidermidis and $P$. aeruginosa $\log _{10}$ concentration were reduced on the glass surface, $-0.395 \mathrm{SD} 0.48,-0.575 \mathrm{SD} 0.853$ and -0.721 SD 0.461 , respectively. These reductions were significantly $(p<0.05)$ greater than those observed with the ex-vivo or the suspension tests. The drying process in the ex-vivo test did not have any significant effect on bacterial survival.

Table 1. Antimicrobial activity of the neutralisers

\begin{tabular}{|c|c|c|c|c|}
\hline \multirow[b]{2}{*}{$\begin{array}{l}\text { Bacterial } \\
\text { strains }\end{array}$} & \multicolumn{4}{|c|}{$\log _{10}$ difference in cell concentration after contact with neutralisers compared with cells in original culture (SD) } \\
\hline & $\begin{array}{c}\text { Neutraliser } \\
\text { A }\end{array}$ & $\begin{array}{c}\text { Neutraliser } \\
\text { B }\end{array}$ & $\begin{array}{c}\text { Neutraliser } \\
\text { C }\end{array}$ & $\begin{array}{c}\text { Neutraliser } \\
\text { D }\end{array}$ \\
\hline S. aureus & $+0.033(0.115)$ & $+0.126(0.124)$ & $+0.092(0.119)$ & $+0.121(0.087)$ \\
\hline MRSA & $+0.177(0.173)$ & $+0.084(0.247)$ & $+0.189(0.135)$ & $+0.049(0.89)$ \\
\hline Ent. faecalis & $+0.181(0.119)$ & $+0.134(0.126)$ & $+0.027(0.191)$ & $+0.035(0.119)$ \\
\hline VRE & $+0.005(0.095)$ & $+0.026(0.145)$ & $+0.025(0.124)$ & $+0.113(0.174)$ \\
\hline S. epidermidis & $+0.167(0.151)$ & $+0.089(0.865)$ & $+0.114(0.119)$ & $+0.225(0.089)$ \\
\hline P. aeruginosa & $+0.151(0.382)$ & $+0.160(0.326)$ & $+0.315(0.286)$ & $-0.071(0.039)$ \\
\hline E. coli & $+0.098(0.152)$ & $+0.049(0.167)$ & $+0.093(0.096)$ & $+0.147(0.224)$ \\
\hline
\end{tabular}

+ , an increase in bacterial titre; - , a reduction in bacterial titre.

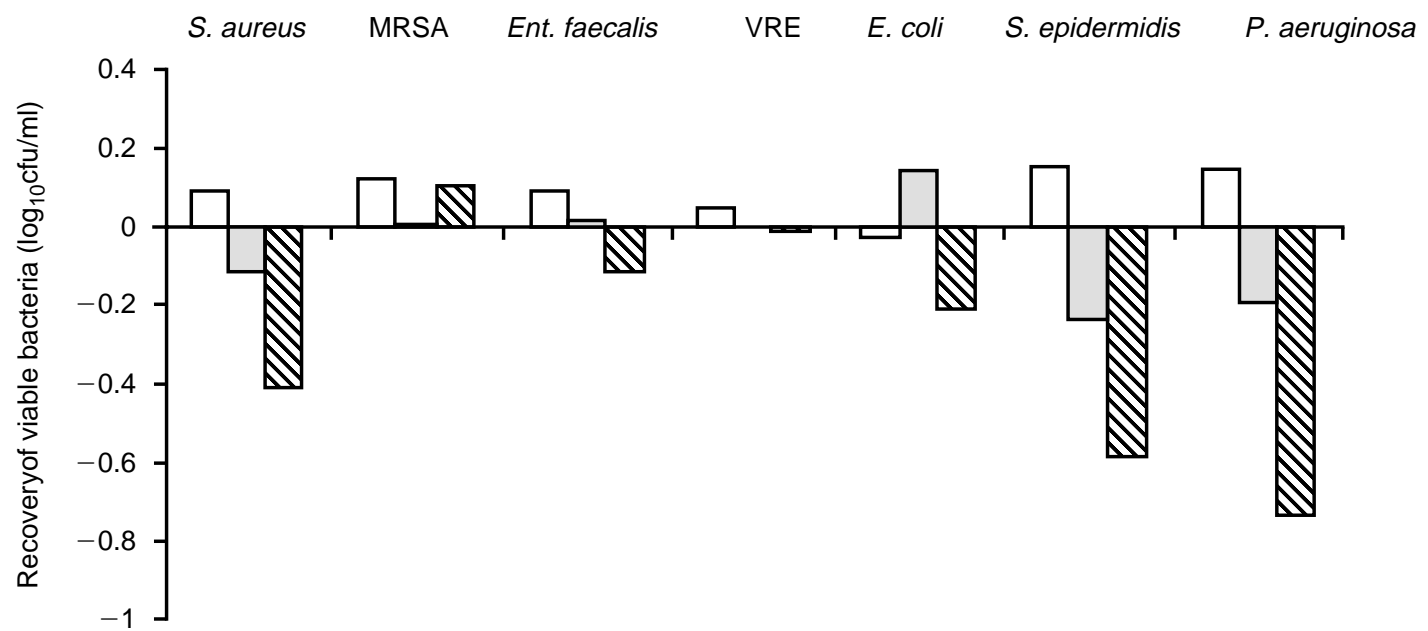

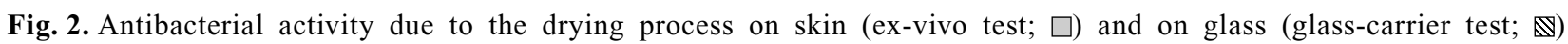
compared to that in the suspension test $(\square)$. 


\section{Skin viability}

Fig. 3 shows the comparison of LDH activity from two samples of skin. For each sample, one piece was used fresh and another was used after being frozen for $24 \mathrm{~h}$ (and then defrosted for $1 \mathrm{~h}$ at room temperature before the first measurement of LDH activity).

The LDH activity measured up to $180 \mathrm{~h}$ after excision showed that the viability of fresh skin is stable. LDH activity of c. $90 \mathrm{U} / \mathrm{L}$ showed that the skin was still viable. When the LDH activity of frozen samples was measured, the results were variable. The LDH activity average was significantly higher $(50-500 \mathrm{U} / \mathrm{L})$ with the frozen samples than with the fresh ones.

Effect of the use of fresh or frozen skin samples on the antibacterial activity of the biocides

There was no significant difference $(p>0.05)$ in the bactericidal activity of biocides tested on fresh or frozen skin, with the exception of PCMX $0.24 \%$ tested against E. coli $(\mathrm{p}<0.05)$. Hence, only the results obtained with the fresh samples were taken into account for subsequent analyses of results with E. coli.

\section{Effect of re-utilisation of the skin samples}

There was no significant difference $(p>0.05)$ in antibacterial activity of the biocides tested between the first and the second use of frozen skin samples. When biocides were tested on fresh skin, there was a significant difference $(\mathrm{p}<0.05)$ in results only when povidone iodine $2 \%$ was tested against $P$. aeruginosa. Hence, only the results from the first use of skin were taken into account for subsequent analyses of results for this combination.
Antibacterial activity of biocides against the bacteria investigated after 1-min contact time with the three protocols

When assessed with the suspension test, there was no significant difference in activity between triclosan $0.5 \%$ in $70 \%$ isopropanol and isopropanol $70 \%$ against all bacterial strains (Fig. 4). With the glass-carrier test, the activity of triclosan in isopropanol was higher than that of isopropanol only, with the exception of $P$. aeruginosa and VRE (Figs. 4a and b). There was also a significant difference in activity between triclosan in isopropanol and isopropanol tested against $S$. epidermidis with, respectively, 4.949 SD 1.276 and 1.847 SD $0.363 \log _{10}$ reduction in bacterial concentration (Fig. 4c). With the ex-vivo test, the antibacterial activity of triclosan in isopropanol appeared to be slightly higher than that of isopropanol against $S$. aureus with, respectively, 1.771 SD 1.142 and 0.511 SD $0.417 \log _{10}$ reduction in bacterial concentration (Fig. 4d) and against MRSA with, respectively, 1.214 SD 0.806 and 0.314 SD $0.099 \log _{10}$ reduction in bacterial concentration (Fig. 4e), even though the difference in efficacy was not statistically significant. There was a significant $(\mathrm{p}<0.05)$ difference in activity of isopropanol between the two in-vitro tests against VRE and $S$. epidermidis (Figs. $4 \mathrm{~b}$ and c). When assessed in the ex-vivo test, isopropanol and triclosan in isopropanol did not show any difference in activity ( $\mathrm{p}>0.05$ ) against MRSA and S. aureus (Figs. 4d and e).

The antibacterial activity of the biocides tested was always higher with the suspension test except for triclosan, for which the antibacterial activity was similar in the suspension and the glass-carrier test. The antibacterial activity of the biocides was always lower when assessed with the ex-vivo test.

There was a significant difference in biocidal activity

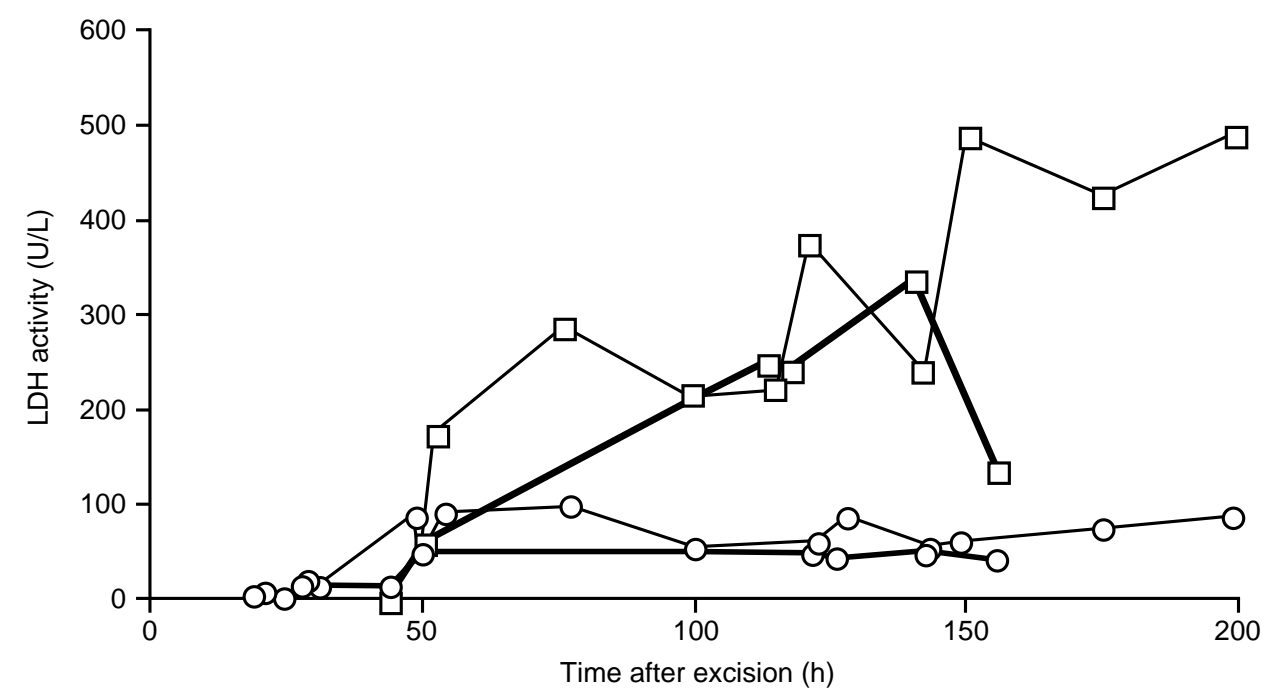

Fig. 3. Comparison of the LDH activity of two samples of fresh skin which were used as fresh skin $\left(1,-\bigcirc_{-} ; 2,-\bigcirc_{-}\right)$ or after being frozen for $24 \mathrm{~h}(1 \mathrm{a},-\square-; 2 \mathrm{a},-\square-)$. 

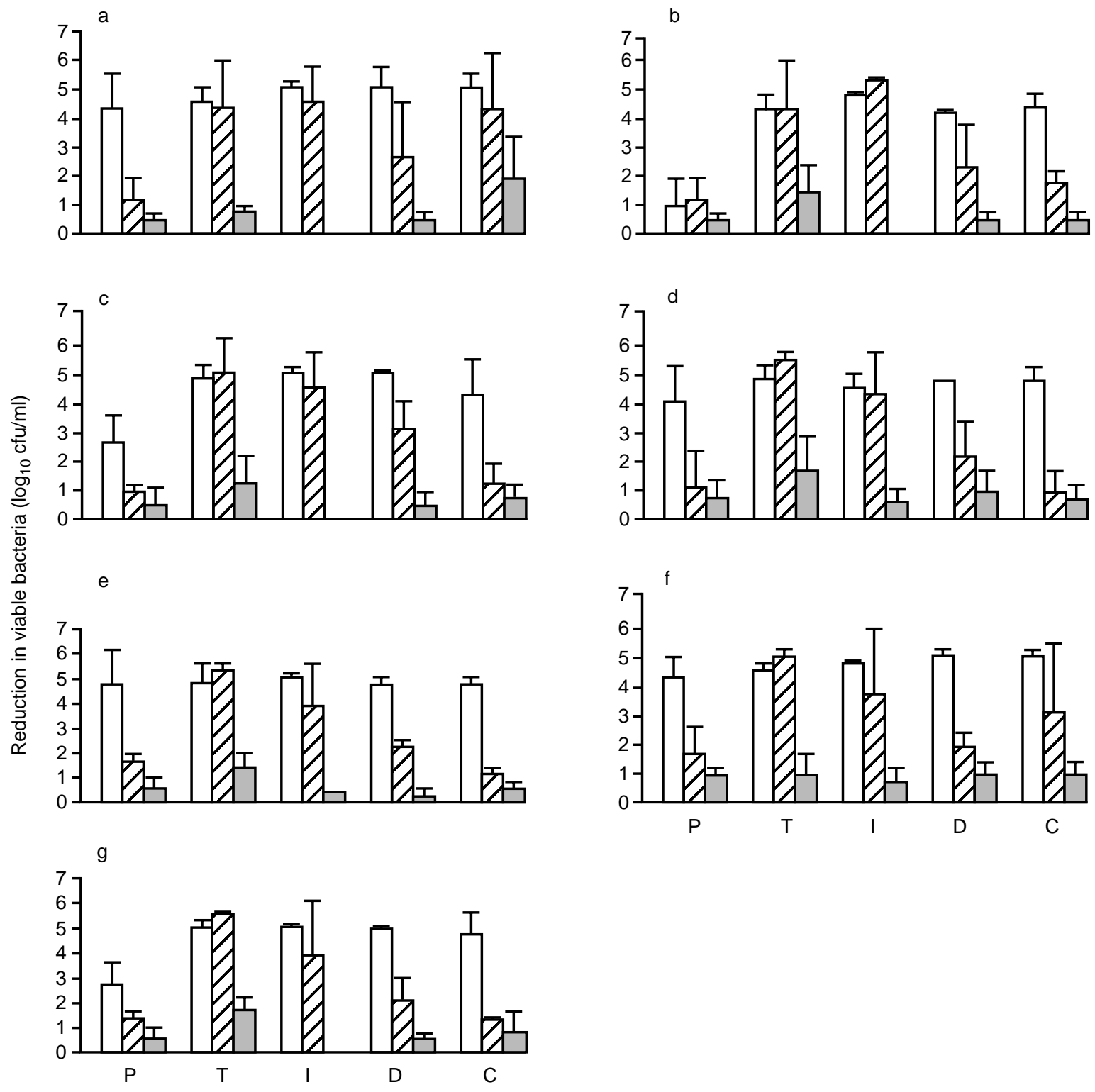

Fig. 4. Antibacterial activity of povidone iodine $2 \%(\mathrm{P})$, triclosan $0.5 \%$ (T), isopropanol $70 \%$ (I), PCMX $0.24 \%$ (D) and chlorhexidine $2 \%$ (C) against (a) P. aeruginosa, (b) VRE, (c) S. epidermidis, (d) S. aureus Oxford, (e) MRSA, (f) E. coli $\mathrm{K} 12$ and (g) Ent. faecalis in the suspension $(\square)$, glass-carrier $(\mathbb{Z})$ and ex-vivo $(\square)$ tests.

of all the agents tested against S. aureus Oxford, E. coli and Ent. faecalis between the tests performed $(\mathrm{p}<0.05$; Fig. $4 \mathrm{~d}, \mathrm{f}$ and $\mathrm{g})$.

With S. aureus Oxford (Fig. 4d), biocidal activity tested in suspension was always significantly $(\mathrm{p}<0.05)$ higher than with the ex-vivo test or with the glass-carrier test except for triclosan in isopropanol, for which the activity was higher in the glass-carrier test. The activity of the biocides was significantly higher $(p<0.05)$ with the glass-carrier test than with the ex-vivo test, for povidone iodine and chlorhexidine for which the activity was not significantly different between these two tests $(\mathrm{p}>0.05)$.

There was no significant difference $(p>0.05)$ in biocidal activity between the glass-carrier and suspension tests when triclosan in isopropanol was assessed against MRSA (Fig. 4e), and when triclosan in isopropanol or povidone iodine were assessed against VRE (Fig. 4b).

The antibacterial activity of chlorhexidine and povidone iodine was not significantly different $(\mathrm{p}>0.05)$ against $P$. aeruginosa when tested with the glass-carrier or the ex-vivo tests (Fig. 4a). Chlorhexidine showed the greatest activity when tested against $P$. aeruginosa in the ex-vivo test $\left(1.947 \mathrm{SD} 1.519 \log _{10}\right.$ reduction in bacterial concentration). Triclosan in isopropanol had the lowest activity (0.758 SD $0.308 \log _{10}$ reduction) against $P$. aeruginosa compared with the other microorganisms investigated. 
Biocides tested against $S$. epidermidis showed a significant difference in activity $(p<0.05)$ depending on the test performed, with the exception of povidone iodine for which activity was not significantly different $(p>0.05)$ in the glass-carrier test and the ex-vivo test (Fig. 4c).

With the ex-vivo test, there was no significant difference in the activity $(\mathrm{p}>0.05)$ of the four agents tested against E. coli (Fig. 4f).

\section{Discussion}

It is known that skin samples taken from living or dead persons retain life function $[11,12]$. It has been shown that cadaver skin can be energy viable for up to 8 days when stored in Eagle's Minimum Essential Medium at $4^{\circ} \mathrm{C}$ [13]. In 1978, clinical experience with frozen autoor allo-grafts showed no significant difference when compared with the use of freshly harvested auto- or allo-grafts [14]. Fresh skin samples used in the present study came from patients undergoing plastic surgery and were immediately placed in EBSS media and refrigerated. They were used within 3 or 4 days. According to Fig. 3, when the viability of fresh samples was assessed, there was no significant variation in $\mathrm{LDH}$ activity within $180 \mathrm{~h}$. It is expected that, at $25^{\circ} \mathrm{C}$, the LDH activity of adults will be 125-236 U/L [15]. The LDH activity measured in the fresh samples was lower at 50-90 U/L once stable.

The results with the frozen samples showed a high variability in LDH activity measurement with values rising to $500 \mathrm{U} / \mathrm{L}$. It has been shown that freezing skin for storage can destroy skin viability [13]. Rises in LDH activity are medically associated with many pathological conditions, which might explain such an augmentation with the frozen skin samples. However, this did not seem to have any effect on the tests performed with both skin preparations, fresh or frozen, as there was no significant difference in biocidal activity, with the exception of PCMX tested against E. coli K12. However, it has to be noted that demonstration of enzyme activity is not necessarily a proof of cell viability and further tests should be conducted [16].

The antibacterial activity of the biocides tested was always highest when assessed by the suspension test and always lowest when assessed by the ex-vivo test. The bactericidal activity of the agents investigated depended on the test performed and the results were generally significantly different between the various methods.

With the suspension test, most of the biocides achieved a $4-5 \log _{10}$ reduction in bacterial concentration after only $1 \mathrm{~min}$, with the exception of povidone iodine that achieved $3 \log _{10}$ reduction with S. epidermidis and Ent. faecalis and only a $1 \log _{10}$ reduction against VRE. Triclosan in isopropanol did not show any significant difference $(p>0.05)$ in activity when tested in the glass-carrier or suspension tests against MRSA and VRE. However, triclosan in isopropanol showed a significant difference $(\mathrm{p}<0.05)$ in activity between these two in-vitro tests when tested against the other bacterial strains, although its antibacterial activity remained high, i.e., $5 \log _{10}$ reduction in bacterial concentration after 1 min contact. Most of the time, the antibacterial activity of the other biocides was significantly lower in the glass-carrier test than in the suspension test, i.e., $1-3 \log _{10}$ difference in bacterial concentration after biocidal challenge.

PCMX $0.24 \%$ (diluted Dettol) has been shown to be highly active in vitro (suspension test) with $>6 \log$ reduction in viable count within $1 \mathrm{~min}$ against $S$. aureus, $5.5 \log _{10}$ reduction against Ent. faecium and $4.9 \log _{10}$ reduction against $P$. aeruginosa [17]. In the present study, 0.24\% PCMX achieved a $4.5-5 \log _{10}$ reduction in viable count after 1 min contact time against all strains in the suspension test. When tested with a surface test on stainless steel disks 5\% Dettol produced, reductions in viable count within $5 \mathrm{~min}$, ranging from 3.5 to $4.5 \log _{10}$ for $S$. aureus, from 2.9 to $>6 \log _{10}$ for P. aeruginosa and from 1.3 to $4.8 \log$ for Ent. faecium [18]. The inactivation results on the glass surface (i.e., glass-carrier test) were significantly lower, although in the present study only 1 min contact time was used. Furthermore, the variability in results remained important: 2.065 SD 1.337, 2.699 SD 1.812 and $2.116 \mathrm{SD} 0.932 \log _{10}$ reduction for $S$. aureus, $P$. aeruginosa and Ent. faecalis respectively. In one invivo study that used artificially contaminated skin, $>99 \%$ reduction in bacterial count was observed after S. aureus, Ent. faecalis, E. coli and P. aeruginosa were challenged with 5\% Dettol for 5 min [19]. With the exvivo test, the antibacterial activity of PCMX against all strains was generally slightly higher than that of povidone iodine and chlorhexidine (with the exception of E. coli), although the difference in activity was not statistically significant. The greatest activity of PCMX was observed when tested against $E$. coli and $S$. aureus, $0.9014 \mathrm{SD} 0.5023$ and $0.8225 \mathrm{SD} 0.8334 \log _{10}$ reduction in bacterial titre respectively.

From another in-vivo study on hands, $0.5 \%$ triclosan in $70 \%$ isopropanol (Manusept), was significantly more active against $E$. coli than $60 \%$ isopropyl alcohol and $0.5 \%$ chlorhexidine in $60 \%$ isopropanol [20]. In the present ex-vivo study $0.5 \%$ triclosan in $70 \%$ isopropanol was significantly more active than $70 \%$ isopropanol alone and than any of the other three biocides investigated after 1 min contact time. Triclosan has been shown to have poor efficacy for gram-negative bacteria in vitro [1] and in vivo [21]. In the present study, triclosan in isopropanol had a high antibacterial activity against gram-negative and gram-positive bacteria with the suspension and with the glass-carrier tests, from 4.5 
to $5 \log _{10}$ reduction in titre $\left(4 \log _{10}\right.$ for P. aeruginosa in the glass-carrier test) after 1 min contact time. Finally, with the ex-vivo test, triclosan in isopropanol was more active against gram-positive bacteria than against both gram-negative strains (E. coli and $P$. aeruginosa) with, respectively $1.105 \mathrm{SD} 0.678 \mathrm{SD} 0.678$ and $0.7585 \mathrm{SD}$ $0.308 \log _{10}$ reduction in viable count after $1 \mathrm{~min}$ contact time. It is possible that the activity of triclosan was potentiated by the alcohol, as isopropanol $70 \%$ showed good efficacy in the glass-carrier and suspension tests. With the ex-vivo and the glass-carrier tests, the antimicrobial activity of triclosan in isopropanol was generally higher than that of isopropanol alone. Isopropanol is known to be an effective antimicrobial agent and is widely used for hard-surface disinfection and skin antisepsis [22]. The isopropanol contained in the triclosan-isopropanol formulation may have a role in its antimicrobial efficacy, as alcohol products added to a low concentration of biocide (triclosan in this case) can enhance the activity of the biocide which remains on the skin after evaporation of the alcohol.

In the in-vitro test results, there was no significant difference in activity $(\mathrm{p}>0.05)$ when the biocides were tested against $S$. aureus or MRSA. In the ex-vivo test, povidone iodine and triclosan in isopropanol did not show any significant $(\mathrm{p}>0.05)$ difference in activity against $S$. aureus and MRSA. These results confirmed other studies in which povidone iodine was shown not to have any significant difference in activity against MRSA or methicillin-sensitive $S$. aureus (MSSA) [23, 24]. Similarly, an investigation of the antibacterial activity of triclosan by a minimum inhibitory concentration method showed no significant difference in activity between MSSA and MRSA [25]. However, it has to be noted that MIC values do not necessarily correlate with bacterial inactivation or minimum bactericidal concentration and in clinical practice, rates of bacterial inactivation are probably more relevant than MIC values [26].

According to a recent in-vivo study, triclosan $1 \%$ (Novaderm $\mathrm{R}$ formulation) was shown to remove effectively $(p<0.05)$ MRSA from the hands of staff volunteers in an acute surgical ward after $30 \mathrm{~s}$ contact, whereas chlorhexidine gluconate $4 \%$ failed to do so [21]. In the present study, triclosan $0.5 \%$ in isopropanol was significantly more effective $(p<0.05)$ against MRSA than chlorhexidine $2 \%$ in the ex-vivo test. Other in-vivo studies have reported successful control or elimination of MRSA after the introduction of triclosan topical antimicrobial formulations [27-30].

Although the antibacterial activity of chlorhexidine and PCMX were statistically significantly $(\mathrm{p}<0.05)$ higher against $S$. aureus than against MRSA, differences remain marginal, with $0.782 \mathrm{SD} 0.496 \log _{10}$ reduction in $S$. aureus concentration and 0.504 SD $0.301 \log _{10}$ reduction in MRSA concentration with chlorhexidine, and $0.822 \mathrm{SD} 0.833 \log _{10}$ reduction in $S$. aureus con- centration and $0.303 \mathrm{SD} 0.253 \log _{10}$ reduction in MRSA concentration with PCMX. Similarly, it was shown in an in-vitro study that chlorhexidine was more active against $S$. aureus than against MRSA [31]. However, Cookson et al. [32] found no difference in the antimicrobial activity of chlorhexidine $4 \%$ between MRSA and MSSA when tested with an in-vivo protocol. Furthermore, some in-vitro studies (MIC and time-kill studies) have shown no difference in antibacterial activity of the biguanide between $S$. aureus and MRSA [33] or when PCMX 1\% was tested [23].

The bactericidal activity of the four biocides tested was not significantly different $(\mathrm{p}>0.05)$ between VRE and E. faecalis in the glass-carrier test. With the suspension test, although the activity of chlorhexidine $2 \%$ and triclosan $0.5 \%$ in isopropanol was the same for these two micro-organisms, the activities of povidone iodine $2 \%$ and PCMX 5\% were marginally higher $(\mathrm{p}<0.05)$ against Ent. faecalis than against VRE. In contrast, in the ex-vivo test, povidone iodine $2 \%$ antibacterial activity was statistically significantly higher $(\mathrm{p}<0.05)$ against VRE than against Ent. faecalis, although results were very similar with, respectively, 0.699 SD 0.31 and $0.427 \mathrm{SD} 0.361 \log _{10}$ reduction in bacterial concentration. Whether such a small difference in activity of biocides against VRE and vancomycin-sensitive enterococci (VSE) is significant in situ remains to be determined. Previous in-vitro studies have also failed to demonstrate a difference in disinfectant susceptibility between VRE and VSE [26, 33-35].

Another study showed that chlorhexidine $4 \%$ and povidone iodine $7.5 \%$ were very effective (i.e., $4 \log _{10}$ reduction after $30 \mathrm{~s}$ contact time) against VRE inoculated on to the skin [36]. This result was much higher than those obtained with the ex-vivo test in the present study. A possible explanation is that in the invivo study, fingertips were rubbed against each other, thus possibly physically removing some micro-organisms from the skin surface, whereas with the ex-vivo test, there was no rubbing effect.

This study showed that the antibacterial activity of four biocides commonly used as handwash products depended upon the procedures used (i.e., in-vitro or exvivo protocol). To date, handwash formulations with antiseptic properties are well documented and investigated in the literature [1], usually on the basis of the results of in-vitro tests. The suspension test protocol has been shown to give an overestimation of the antibacterial activity of biocides investigated [5]. The glass-carrier test is not always reliable because of the significant loss of bacterial cells from the drying step. The ex-vivo test provides a close imitation of human skin behaviour, although there is no longer any vascularisation or glands going to the dermis or basal layers. However, this should be of little significance for the testing of antiseptics, because the stratum corneum 
is essentially a non-living tissue. This protocol is easy to use and allows the testing of pathogenic microorganisms [5,37]. Because of the emergence of antibiotic-resistant micro-organisms such as MRSA and VRE, it is becoming increasingly necessary to be able to assess biocidal activity of an antiseptic directly on skin. This comment is particularly pertinent since the results showed that there was a significant difference in the activity of biocides depending on the test used. Finally, this study confirmed that the ex-vivo method should be useful for manufacturers of antimicrobial agents and regulatory agencies to ensure that commercially available formulations meet their claims when used according to manufacturers' instructions [6].

We thank Reckitt \& Colman for the financial support and Miss Ying Hui Teo for providing the skin samples.

\section{References}

1. Hugo WB, Russell AD. Types of antimicrobial agents. In: Russell AD, Hugo WB, Ayliffe GAJ (eds) Principles and practice of disinfection, preservation, and sterilization, 2nd edn. Oxford, Blackwell Scientific Publications. 1992: 7-88.

2. Gould D. Nurses' hand decontamination practice: results of a local study. J Hosp Infect 1994; 28: 15-30.

3. Pereira LJ, Lee GM, Wade KJ. An evaluation of five protocols for surgical handwashing in relation to skin condition and microbial counts. J Hosp Infect 1997; 36: 49-65.

4. Kirita T, Hamano K, Ochi T et al. Efficacy and safety of a quick drying rubbing type povidone-iodine alcoholic disinfectant solution. Postgrad Med J 1993; 69 Suppl 3: S27-S32.

5. Maillard JY, Messager S, Veillon R. Antimicrobial efficacy of biocides tested on skin using an ex-vivo test. J Hosp Infect 1998; 40: 313-323.

6. British Pharmacopeia 1993. Vol II, Appendix XVIII, A197.

7. Chemical disinfectants and antiseptics - Hygienic Handwash Test method and requirements (phase 2/step 2). British Standard EN 1499: 1997.

8. Chemical disinfectants and antiseptics - Quantitative suspension test for the evaluation of bactericidal activity of chemical disinfectants and antiseptics used in food, industrial, domestic, and industrial areas - Test method and requirements (phase 2, step 1). British Standard EN 1276: 1997.

9. Walsh SE, Maillard JY, Russell AD. Ortho-phthalaldehyde: a possible alternative to glutaraldehyde for high level disinfection. J Appl Microbiol 1999; 86: 1039-1046.

10. Best M, Sattar SA, Springthorpe VS, Kennedy ME. Comparative mycobactericidal efficacy of chemical disinfectants in suspension and carrier tests. Appl Environ Microbiol 1988; 54: $2856-2858$.

11. Girdner JH. Skin grafting with grafts taken from the dead subject. Med Rec (New York) 1881; 20: 119.

12. Brewer EP. On the limit of skin vitality. Med Rec (New York) 1882; 27: 483.

13. Wester RC, Christoffel J, Hartway T, Poblete N, Maibach HI, Forsell J. Human cadaver skin viability for in vitro percutaneous absorption: storage and detrimental effects of heatseparation and freezing. Pharm Res 1998; 15: 82-84.

14. Burke JF. Contribution of frozen skin bank to treatment of massive burns. Acta Med Pol 1978; 19: 283-288.

15. Weisshaar D, Gossau E, Faded B. Normbereich von $\alpha-\mathrm{HBDH}$, LDH, AP und LAP bei messung mit substrat-optimierten testansatzen. Med Welt 1975; 26: 387-390.

16. Jensen HS. Skin viability studies in vitro. Scand J Plast Reconstr Surg 1984; 18: 55-59.
17. Bloomfield SF, Arthur M, Looney E, Begun K, Patel H. Comparative testing of disinfectant and antiseptic products using proposed European suspension testing methods. Lett Appl Microbiol 1991; 13: 233-237.

18. Bloomfield SF, Arthur M, Begun K, Patel H. Comparative testing of disinfectants using proposed European surface test methods. Lett Appl Microbiol 1993; 17: 119-125.

19. Munton TJ, Prince J. The bactericidal activity of Dettol on skin artificially contaminated with micro-organisms using the replica plating technique. 1975; R\&C SORL BL 75/12.

20. Bartzokas CA, Gibson MF, Graham R, Pinder DC. A comparison of triclosan and chlorhexidine preparations with 60 per cent isopropyl alcohol for hygienic hand disinfection. J Hosp Infect 1983; 4: 245-255.

21. Faoagali JL, George N, Fong J, Davy J, Dowser M. Comparison of the antibacterial efficacy of $4 \%$ chlorhexidine gluconate and $1 \%$ triclosan handwash products in an acute clinical ward. Am J Infect Control 1999; 27: 320-326.

22. McDonnell G, Russell AD. Antiseptics and disinfectants: activity, action, and resistance. Clin Microbiol Rev 1999; 12: 147-179.

23. Haley CE, Marling-Carson M, Smith JW, Luby JP, MacKowiak PA. Bactericidal activity of antiseptics against methicillinresistant Staphylococcus aureus. J Clin Microbiol 1985; 21: 991-992.

24. Lacey RW, Catto A. Action of povidone-iodine against methicillin-sensitive and -resistant cultures of Staphylococcus aureus. Postgrad Med J 1993; 69 Suppl 3: S78-S83.

25. Bamber AI, Neal TJ. An assessment of triclosan susceptibility in methicillin-resistant and methicillin-sensitive Staphylococcus aureus. J Hosp Infect 1999; 41: 107-109.

26. Suller MTE, Russell AD. Antibiotic and biocide resistance in methicillin-resistant Staphylococcus aureus and vancomycinresistant enterococcus. J Hosp Infect 1999; 43: 281-291.

27. Zafar AB, Butler RC, Reese DJ, Gaydos LA, Mennonna PA. Use of $0.3 \%$ triclosan (Bacti-Stat) to eradicate an outbreak of methicillin-resistant Staphylococcus aureus in a neonatal nursery. Am J Infect Control 1995; 23: 200-208.

28. Webster J, Faoagali JL, Cartwright D. Elimination of methicillin-resistant Staphylococcus aureus from a neonatal intensive care unit after hand washing with triclosan. J Paediatr Child Health 1994; 30: 59-64.

29. Brady LM, Thomson M, Palmer MA, Harkness JL. Successful control of endemic MRSA in a cardiothoracic surgical unit. Med J Aus 1990; 152: 240-245.

30. Tuffnell DJ, Croton RS, Hemingway DM, Hartley MN, Wake PN, Garvey RJP. Methicillin-resistant Staphylococcus aureus; the role of antisepsis in the control of an outbreak. $J$ Hosp Infect 1987; 10: 255-259.

31. Kampf G, Jarosch R, Rüden H. Limited effectiveness of chlorhexidine based hand disinfectants against methicillinresistant Staphylococcus aureus (MRSA). J Hosp Infect 1998; 38: 297-303.

32. Cookson BD, Bolton MC, Platt JH. Chlorhexidine resistance in methicillin-resistant Staphylococcus aureus or just an elevated MIC? An in vitro and vivo assessment. Antimicrob Agents Chemother 1991; 35: 1997-2002.

33. Haines KA, Klein DA, McDonnell G, Pretzer D. Could antibiotic-resistant pathogens be cross-resistant to hard-surface disinfectants? Am J Infect Control 1997; 25: 439-441.

34. Anderson RL, Carr JH, Bond WW, Favero MS. Susceptibility of vancomycin-resistant enterococci to environmental disinfectants. Infect Control Hosp Epidemiol 1997; 18: 195-199.

35. Kampf G, Höfer M, Wendt C. Efficacy of hands disinfectants against vancomycin-resistant enterococci in vitro. $J$ Hosp Infect 1999; 42: $143-150$.

36. Wade JJ, Desai N, Casewell MW. Hygienic hand disinfection for the removal of epidemic vancomycin-resistant Enterococcus faecium and gentamicin-resistant Enterobacter cloacae. J Hosp Infect 1991; 18: 211-218.

37. Graham ML, Springthorpe VS, Satter SA. Ex vivo protocol for testing virus survival on human skin: experiments with herpesvirus 2. Appl Environ Microbiol 1996; 62: 4252-4255. 